\title{
Effects of Endurance Training and Isocaloric High Intensity Interval Training on Anthropometric Indices and Insulin Resistance in High Fat Diet-Fed Wistar Rats
}

\author{
Seyed Javad Mirghani (PhD \\ Candidate) \\ Department of Exercise Physiology, \\ Faculty of Physical Education and \\ Sports Science, Islamic Azad \\ University, Central Tehran Branch, \\ Tehran, Iran \\ Mohammad Ali Azarbayjani (PhD) \\ Professor of Exercise Physiology, \\ Department of Exercise Physiology, \\ Faculty of Physical Education and \\ Sports Science, Islamic Azad \\ University, Central Tehran Branch, \\ Tehran, Iran \\ Maghsoud Peeri (PhD) \\ Professor of Exercise Physiology, \\ Department of Exercise Physiology, \\ Faculty of Physical Education and \\ Sports Science, Islamic Azad \\ University, Central Tehran Branch, \\ Tehran, Iran \\ Corresponding author: \\ m_azarbayjani@iauctb.ac.ir \\ Email: m_azarbayjani@iauctb.ac.ir \\ Tel: +989120747177 \\ Address: Artesh high highway \\ Sohanak, Islamic Azad University \\ Central Tehran Branch Tehran Iran. \\ Received: 08 May 2018 \\ Revised: 02 Aug 2018 \\ Accepted: 29 Aug 2018
}

\begin{abstract}
Background and Objectives: 0besity is a global health problem that could lead to cardiovascular disease, diabetes and cancer. Polygenic obesity is caused by multiple factors, such as lack of exercise and excess food intake. In this study, we evaluated effects of 12 weeks of high-intensity interval training (HIIT) and isocratic moderate-intensity training (IIT) on anthropometric indices and insulin resistance in rats fed with a high-fat diet (HFD). Methods: Twenty-five male Wistar rats (mean age of 5-6 weeks) were divided into three groups: control group (HFD, N=5), HFD+ MIT $(\mathrm{N}=10)$ and HFD+ HIIT $(\mathrm{N}=10)$. After placing the subjects on a HFD for 13 weeks, the exercise groups performed trainings for 12 weeks.

Results: Body mass index and Lee index decreased significantly in both training groups $(\mathrm{P} \leq 0.05)$. There was no significant difference in insulin resistance between the three groups $(\mathrm{P}>0.05)$.

Conclusion: Based on the results, it can be concluded that HIIT is more effective than MIT in reducing some of the obesity markers in obese rats fed with a HFD. However, this type of training has no significant impact on insulin resistance.

Keywords: 0besity, High Intensity Interval Training, High-Fat Diet, Body composition Indexes.
\end{abstract}




\section{INTRODUCTION}

The prevalence of obesity is increasing rapidly in both developing and developed countries. According to the latest statistics, more than $35 \%$ of the world's population has a body mass index (BMI) higher than the normal value $\left(18\right.$ to $\left.25 \mathrm{Kg} / \mathrm{cm}^{2}\right)$ and this trend is increasing every year $(1,2)$. Polygenic obesity and the subsequent excess weight gain has various psychosocial consequences (3). Obesity and its complications such as type 2 diabetes, hypertension, coronary artery disease and cancer may eventually cause morbidity and mortality (4, 5). Furthermore, several factors such as increased calorie intake, reduced energy expenditure (6), food intake (7), environmental changes and genetic factors have a significant correlation with the prevalence of polygenic obesity and general obesity (8). However, there is no compelling evidence to confirm a correlation between obesity and dietary fat types in body composition changes (9). Obesity may cause various diseases such as stroke, inflammation and hypercholesterolemia (10). Factors such as time constraints and increasing consumption of fast food contribute to change in body weight and body composition (11). Lack of activity (12), excessive caloric intake, a highfat and high-sugar diet and reduced physical activity are risk factors for insulin resistance and weight gain (13). Different strategies such as medications and calorie restriction have been used to control weight and reduce anthropometric indices (14). On the other hand, the importance of physical activity for preventing weight gain, increased body fat and hyperglycemia has been well documented in animal and human studies $(15,16)$. Moreover, studies on HFD fed rats showed that exercise also reduce visceral fat, body weight, food intake (17) and fat mass (18). Some studies suggest that intense exercise may be more effective in improving body composition and weight loss (19). Metabolic indicators are associated with type 2 diabetes and obesity (20). Meanwhile, high-intensity training (HIT) and continues exercise training along with a HFD decreased fat mass and slowed down weight gain (21). Rocha et al. observed that high-intensity endurance swimming in rats on a HFD can reduce food intake, food consumption and nutritional and energy efficiency (22). According to some studies, high-intensity interval training
(HIIT)has a more profound effect than endurance training on weight loss, glucose control and insulin resistance $(23,24)$. However, a study claimed that glucose control, insulin resistance and weight gain are not affected by HIIT (25). In the present study, we evaluate the effect of 12 weeks of HIIT and isocratic endurance training on anthropometric indices and insulin resistance in HFD fed rats.

\section{MATERIAL AND METHODS}

Twenty-five Wistar rats aged 5-6 weeks with mean weight of $128.32 \mathrm{~g}$ were purchased from the Pastor Institute, Iran. The animals were kept under suitable laboratory conditions and a 12:12 light:dark cycle, at $22 \pm 3{ }^{\circ} \mathrm{C}$. The study was carried out in two stages: placing rats under a diet with $40 \%$ fat (including 20\% soybean oil and $20 \%$ animal fat) for 13 weeks and 12 weeks of training. After the animals became adopted to the environment for one week, they were divided into three weightmatched groups: control group (HFD, N=5), moderate-intensity training (MIT) with HFD group (MIT+HFD, N=10) and HIIT group $(\mathrm{N}=10)$. The study received approval from the Ethics Committee of the Institute of Physical Education and Sport Sciences Research of Iran.

Exercise training was performed on a treadmill (10 line with 0.1-3.1 MA shocker, made in Iran). The training group became familiar with the trainings for a week and then performed the exercise program by running at speeds of $6,8,10 \mathrm{~m} / \mathrm{min}$. The Bedford method was used to determine the maximal oxygen consumption (26). According to the protocol, the maximum speed at which each rat ran at $0 \%$ inclination until exhaustion was recorded (27). Since this study shows a significant correlation between the velocity of the treadmill and the $\mathrm{VO}_{2} \max$ of rats ( $\mathrm{r}=0.94-0.984, \mathrm{P}<0.0005)$ (28). After taking two days of rest, the average speed was evaluated and all subjects in the training groups were scored by the above-mentioned test. The designed exercise program included HIIT with $85-90 \%$ of $\mathrm{V}_{\max }$, which is equivalent to 7 interval bouts of one-minute at intensity of $31 \mathrm{~m} / \mathrm{min}$ and 6 interval bouts of active rest with intensity of $15 \mathrm{~m} / \mathrm{min}$ in the first week. The training intensity increased gradually by increasing the speed of treadmill by $2 \mathrm{~m} / \mathrm{min}$ per week, until the intensity reached $55 \mathrm{~m} / \mathrm{min}$. 
In week 12, the exercise training consisted of 10 interval bouts of one-minute, and the speed of active rest between the intervals reached 25 $\mathrm{m} / \mathrm{min}$. Endurance training with a moderate intensity (55\% of $\mathrm{V}_{\max }$ ) was performed at 20 $\mathrm{m} / \mathrm{min}$ for $15 \mathrm{~min}$ and $21 \mathrm{sec}$ in the first week, and the training intensity was gradually increased to $25 \mathrm{~m} / \mathrm{min}$ for 31 minutes in week 12. Warm up included 3 minutes of running at intensity of $10 \mathrm{~m} / \mathrm{min}$, followed by 2 minutes of running at intensity of $15 \mathrm{~m} / \mathrm{min}$. Cool down consisted of one-minute running at intensity of $15 \mathrm{~m} / \mathrm{min}$, followed by 2 minutes of running at $10 \mathrm{~m} / \mathrm{min}$. In order to study the effects of each exercise mode, the exercise volume (in terms of calorie expenditure) for both training exercises (HIIT, MIT) was matched in terms of distance travelled $(\mathrm{m} / \mathrm{min})$ to mimic weekly isocaloric exercise. The rats in the exercise groups performed trainings five sessions a week for 12 weeks, with two days of rest per week. In fact, the covered running distance has been used primarily to match the exercise volume across sessions, disregarding of differences in energy expenditure. During the exercise program, three rats were excluded due to sudden death.

After the end of the training, the rats rested for 18 hours based on the recommendations (29). After 24 hours of rest and 6-8 hours of fasting to prevent the acute effects of exercise, the rats were anesthetized by infusion of pentobarbital sodium $(40 \mathrm{mg} / \mathrm{Kg}$; ip). Then, blood samples $(1 \mathrm{ml})$ were taken directly from the heart of each rat. To separate the serum, each sample was centrifuged at 3,000 rpm for 30 minutes at $4{ }^{\circ} \mathrm{C}$. Glucose and insulin (with rat-specific ELISA kit, Cat No: 10-1250-01) levels were measured by an automated analyzer (Alpha Classic) and using rat-specific ELISA kits (Cat No: 10-1250-01, Lot No.25692). Homeostasis model assessment-insulin resistance was used to evaluate insulin resistance (fasting serum insulin $(\mu \mathrm{U} / \mathrm{ml}) \times$ fasting plasma glucose (mmol 1-1)/22.5). The HFD contained the followings: $40 \%$ fat, $14.1 \%$ protein, $36.58 \%$, carbohydrate, $8.4 \%$ minerals and $0.72 \%$ vitamin. Food intake was calculated by recording the difference in diet and the amount of food left overnight during the 13-week study period. Anthropometrics including bodyweight $(\mathrm{g})$, body length $(\mathrm{cm}$, from the tip of the nose to the anus), the Lee index (the third root of the weight $(\mathrm{g}) /$ nasal tip to the anus) and BMI $\left(\mathrm{Kg} / \mathrm{m}^{2}\right)$ were measured for all subjects. The proportion of food consumption to weight gain $(\mathrm{g})$ was recorded as the feed efficiency, while the weight gain $(\mathrm{g})$ to total calorie intake (Kcal) ratio was calculated as the energy efficiency.

Data were analyzed by SPSS software (version 16) using ANOVA. The Tukey's post hoc test was used to determine the inter-group differences based on the equality of variances. The statistical significance level was set at 0.05 .

\section{RESULTS}

The level of glucose, insulin and insulin resistance did not differ significantly between the study groups (Figures 1-3). The results also showed that weight $(\mathrm{P}=0.16, \mathrm{~F}=2.018)$, weight gain/total food intake ratio $(\mathrm{P}=0.448, \mathrm{~F}=0.833)$ and total weight gain/total calorie intake ratio $(\mathrm{P}=0.448, \quad \mathrm{~F}=0.833)$ did not change significantly after the exercise training program in the study groups. However, BMI and the Lee index were significantly lower in the HIIT and MIT groups compared with the control group. In addition, total food consumption and total calorie intake decreased significantly in the HIIT group compared to the control group (Table 1). There was no significant difference in feed efficiency and energy efficiency between the study groups $(\mathrm{P}>0.05)$.

Figure 1- Effects of exercise type on serum level of glucose in rats on a HFD. Data are reported as mean \pm SD. The results of ANOVA showed no significant difference between the three groups $(\mathbf{P}>0.05)$.

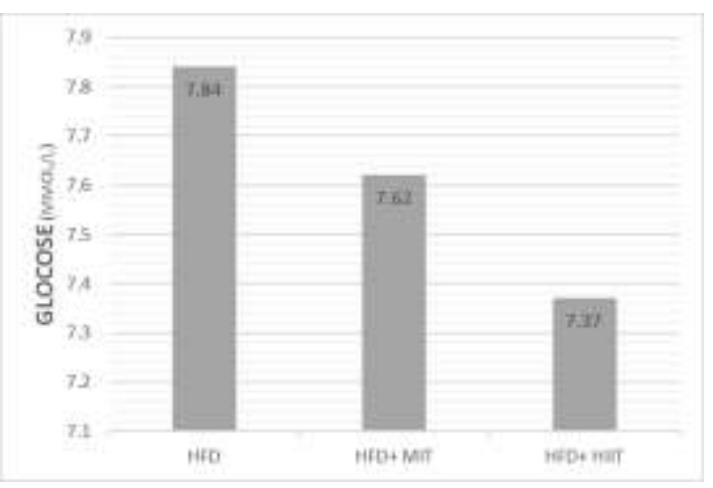


Table 1- Anthropometric indices and mean intragroup differences between the pretest and posttest stages

\begin{tabular}{|c|c|c|c|c|}
\hline Variables & Groups & $\mathbf{N}$ & $\begin{array}{c}\text { Mean difference } \pm \\
\text { standard deviation } \\
\text { (SD) }\end{array}$ & $\mathbf{P}$ \\
\hline Weight & $\begin{array}{c}\text { HFD+Control } \\
\text { HFD+HIIT } \\
\text { HFD+MIT }\end{array}$ & $\begin{array}{c}5 \\
7 \\
10\end{array}$ & $\begin{array}{c}80.4 \pm 29.49 \\
45.79 \pm 13.47 \\
61.56 \pm 36.4\end{array}$ & 0.16 \\
\hline Height & $\begin{array}{c}\text { HFD+Control } \\
\text { HFD+HIIT } \\
\text { HFD+MIT }\end{array}$ & $\begin{array}{c}5 \\
7 \\
10\end{array}$ & $\begin{array}{l}0.94 \pm 0.43 \\
2.6 \pm 0.55 \\
2.2 \pm 0.85\end{array}$ & - \\
\hline BMI & $\begin{array}{c}\text { HFD+Control } \\
\text { HFD+HIIT } \\
\text { HFD+MIT }\end{array}$ & $\begin{array}{c}5 \\
7 \\
10\end{array}$ & $\begin{array}{c}0.107 \pm 0.079 \\
-0.107 \pm 0.042 \\
-0.022 \pm 0.095\end{array}$ & 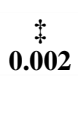 \\
\hline Lee Index & $\begin{array}{c}\text { HFD+Control } \\
\text { HFD+HIIT } \\
\text { HFD+MIT }\end{array}$ & $\begin{array}{c}5 \\
7 \\
10\end{array}$ & $\begin{array}{c}0.0115 \pm 0.0123 \\
-0.024 \pm 0.008 \\
-0.014 . \pm 0.017\end{array}$ & $\begin{array}{c}\ddagger \\
0.001\end{array}$ \\
\hline $\begin{array}{l}\text { Total food } \\
\text { consumption }\end{array}$ & $\begin{array}{c}\text { HFD+Control } \\
\text { HFD+HIIT } \\
\text { HFD+MIT }\end{array}$ & $\begin{array}{c}5 \\
7 \\
10\end{array}$ & $\begin{array}{c}517.68 \pm 524.15 \\
-141.57 \pm 213.99 \\
274.57 \pm 497.71\end{array}$ & $\begin{array}{c}\ddagger \\
0.032\end{array}$ \\
\hline $\begin{array}{l}\text { Total energy } \\
\text { expenditure }\end{array}$ & $\begin{array}{c}\text { HFD+Control } \\
\text { HFD+HIIT } \\
\text { HFD+MIT }\end{array}$ & $\begin{array}{c}5 \\
7 \\
10\end{array}$ & $\begin{array}{c}3009.9 \pm 3053.3 \\
-823.13 \pm 1244.2 \\
1596.4 \pm 2893.7\end{array}$ & $\stackrel{+}{+}$ \\
\hline $\begin{array}{c}\text { Weight gain/Total food } \\
\text { consumption ratio }\end{array}$ & $\begin{array}{c}\text { HFD+Control } \\
\text { HFD+HIIT } \\
\text { HFD+MIT }\end{array}$ & $\begin{array}{c}5 \\
7 \\
10\end{array}$ & $\begin{array}{c}-\mathbf{0 . 0 5 6} \pm \mathbf{0 . 1 0 9} \\
-\mathbf{0 . 0 7 3} \pm \mathbf{0 . 0 2 7} \\
\mathbf{0 . 0 0 4} \pm \mathbf{0 . 0 5 8}\end{array}$ & 0.448 \\
\hline $\begin{array}{l}\text { Weight gain/Total } \\
\text { energy consumption } \\
\text { ratio }\end{array}$ & $\begin{array}{c}\text { HFD+Control } \\
\text { HFD+HIIT } \\
\text { HFD+MIT }\end{array}$ & $\begin{array}{c}5 \\
7 \\
10\end{array}$ & $\begin{array}{c}-0.0096 \pm 0.0188 \\
-0.0126 \pm 0.005 \\
0.0007 \pm 0.009\end{array}$ & 0.448 \\
\hline
\end{tabular}

Data are presented as mean differences between baseline and posttest data.

\pm indicates statistically significant difference.

Figure 2- Effects of exercise type on serum level of insulin in rats on a HFD. Data are reported as mean $\pm \mathrm{SD}$. The results of ANOVA showed no significant difference between the three groups $(\mathrm{P}>0.05)$.

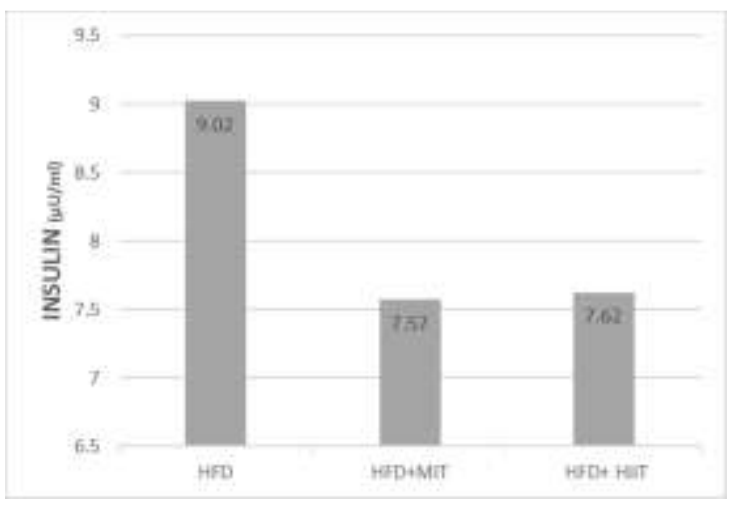

Figure 3- Effects of exercise type on insulin resistance in rats on a HFD. Data are reported as mean $\pm \mathrm{SD}$. The results of ANOVA showed no significant difference between the three groups $(\mathbf{P}>\mathbf{0 . 0 5})$.

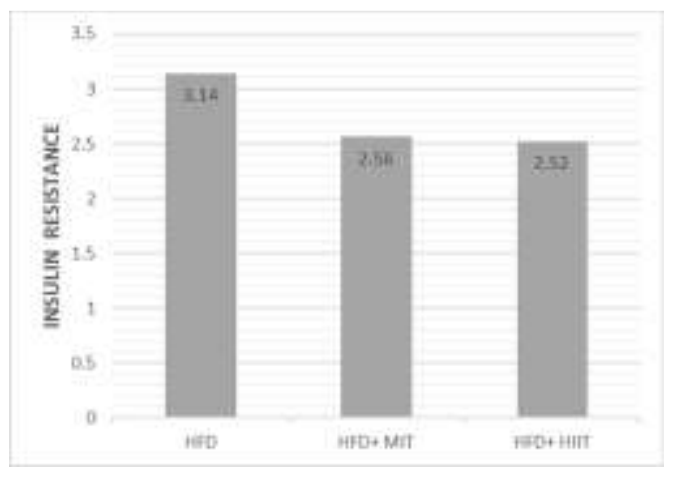




\section{DISCUSSION}

The most important finding of this study was the significant change in the BMI and Lee index in the HIIT and MIT groups compared with the control group. In this regard, the positive effects of HIIT and low intensity interval training on fat accumulation following HFD have been reported (30). Furthermore, weight gain was prevented after 250 to 300 minutes of weekly endurance training. The exercise program also had a significant effect on weight of rats in the training groups. On the other hand, another study showed that exercise and unsaturated fat consumption had significant effects on the treatment group (7). Anthropometrical indices, such as nutritional homeostasis can be used for maintaining health by coordinating daily activities, patterns of food intake, energy consumption and energy storage (31). In a study, eight weeks of swimming in subjects on a HFD reduced the Lee index (16), which is consistent with the results obtained in our study. The results of this study indicate that the decrease in BMI and the Lee index is a synergic impact of HIIT and isocaloric MIT. In line with this finding, Carter et al. showed that reduction of the Lee index and triglyceride level was related to exercise-induced energy expenditure (32). The effect of HIIT on these indices is more profound compared to that of MIT. Therefore, one can conclude that physical activity and its volume influence energy expenditure. Regarding the weightrelated indices, we observed a reduction in calorie consumption and total food intake in the HIIT and the MIT+HFD groups compared with the control group. However, this reduction was less evident in the MIT group. Results of most previous studies on exerciseinduced changes in calorie consumption and energy expenditure are inconclusive and contradictory. A study suggested that significant reductions in resting metabolic rate are due to weight loss (33). Decreased food and calorie intake and the subsequent reduction in body weight are resulted from increased level of leptin. Conversely, lowering this hormone increases leptin resistance and obesity in 12-week-old rats. In addition, calorie and food intake increase in response to reduced leptin level, which results in weight gain and fat mass increase associated with glucose tolerance (34). Regarding the stimulatory effect of exercise on leptin level, the significant reduction in the calorie intake in the HIIT group compared to the endurancetraining group can be attributed to the higher increase of leptin in response to HIIT. On the other hand, food is metabolized to preserve the basal metabolic rate, warmth and muscle activity (energy expenditure). In addition, some neurotransmitters, such as orexin can have a great role in regulation of food intake and appetite (35). The exercise intensity could be another factor involved in body fat and body weight changes and further reduction of food intake and other anthropometric indices in the HIIT group. On the other hand, weight loss and decreased insulin resistance following HIIT have been reported $(28,36)$. However, in the present study, some of the body composition indices reduced in the training groups without a notable change in insulin resistance. It has been demonstrated that HIIT stimulates muscle glycogen while moderate exercise for less than an hour does not. In addition, consuming a HFD, calorie imbalance, increased insulin resistance and decreased insulin sensitivity are other factors that can have a big impact on body fat indices.

\section{CONCLUSION}

Based on our findings, it can be concluded that HIIT could be more effective than isolcaloric MIT for weight loss and reduction of BMI, the Lee index and calorie intake in subjects on a HFD.

\section{ACKNOWLEDGMENTS}

The authors are grateful to Dr Arash Hossein-nezhad for providing the research facilities. We would also like to thank the Shahid Mirghani Research Institute.

\section{CONFLICT OF INTEREST} declare.

There is no conflict of interest to 


\section{REFERENCES}

1. Ng M, Fleming T, Robinson M, Thomson B, Graetz $\mathrm{N}$, Margono C, et al. Global, regional, and national prevalence of overweight and obesity in children and adults during 1980-2013: a systematic analysis for the Global Burden of Disease Study 2013. The lancet. 2014; 384(9945): 766-81.

2. Ogden CL, Carroll MD, Kit BK, Flegal KM. Prevalence of childhood and adult obesity in the United States, 2011-2012. Jama. 2014; 311(8): 806-14.

3. Björntorp P. Do stress reactions cause abdominal obesity and comorbidities?. Obesity reviews. 2001; 2(2): 73-86.

4. Calle EE, Rodriguez C, Walker-Thurmond K, Thun MJ. Overweight, obesity, and mortality from cancer in a prospectively studied cohort of US adults. N Engl j Med. 2003; 2003(348): 1625-38.

5. Must A, Spadano J, Coakley EH, Field AE, Colditz G, Dietz WH. The disease burden associated with overweight and obesity. Jama. 1999; 282(16): 1523-9.

6. Spiegelman BM, Flier JS. Obesity and the regulation of energy balance. Cell. 2001; 104(4): 531-43.

7. Vergoni AV, Poggioli R, Bertolini A. Corticotropin inhibits food intake in rats. Neuropeptides. 1986; 7(2): 153-8.

8. Rankinen T, Zuberi A, Chagnon YC, Weisnagel SJ, Argyropoulos G, Walts B, et al. The human obesity gene map: the 2005 update. Obesity. 2006; 14(4): 529-644.

9. Swithers SE, Ogden SB, Davidson TL. Fat substitutes promote weight gain in rats consuming high-fat diets. Behavioral neuroscience. 2011; 125(4): 512-8.

10. Shin JY, Xun P, Nakamura Y, He K. Egg consumption in relation to risk of cardiovascular disease and diabetes: a systematic review and meta-analysis. The American journal of clinical nutrition. 2013: 146-59. doi: 10.3945/ajcn.112.051318.

11. Pan DA, Storlien LH. Dietary lipid profile is a determinant of tissue phospholipid fatty acid composition and rate of weight gain in rats. The Journal of nutrition. 1993; 123(3): 512-9.

12. Pedersen BK, Febbraio MA. Muscles, exercise and obesity: skeletal muscle as a secretory organ. Nature Reviews Endocrinology. 2012; 8(8): 457-65.

13. Johnson RK, Appel LJ, Brands M, Howard BV, Lefevre M, Lustig RH, et al. Dietary sugars intake and cardiovascular health. Circulation. 2009 Sep 15;120(11):1011-20.

14. Fontana L, Meyer TE, Klein S, Holloszy JO. Longterm calorie restriction is highly effective in reducing the risk for atherosclerosis in humans. Proceedings of the National Academy of Sciences of the United States of America. 2004; 101(17): 6659-63.

15. Bradley RL, Jeon JY, Liu FF, Maratos-Flier E. Voluntary exercise improves insulin sensitivity and adipose tissue inflammation in diet-induced obese mice. American Journal of Physiology-Endocrinology and Metabolism. 2008; 295(3): E586-94.
16. Huang P, Li S, Shao M, Qi Q, Zhao F, You J, Mao T, Li W, Yan Z, Liu Y. Research Calorie restriction and endurance exercise share potent anti-inflammatory function in adipose tissues in ameliorating diet-induced obesity and insulin resistance in mice. Nutr Metab (Lond). 2010; 7: 59. doi: 10.1186/1743-7075-7-59.

17. Lin S, Thomas TC, Storlien LH, Huang XF. Development of high fat diet-induced obesity and leptin resistance in $\mathrm{C} 57 \mathrm{Bl} / 6 \mathrm{~J}$ mice. International journal of obesity. 2000; 24(5): 639-646.

18. Ferrante AW. Obesity-induced inflammation: a metabolic dialogue in the language of inflammation. Journal of internal medicine. 2007; 262(4): 408-14.

19. Colberg SR, Sigal RJ, Fernhall B, Regensteiner JG, Blissmer BJ, Rubin RR, et al. Exercise and type 2 diabetes. Diabetes care. 2010; 33(12): e147-67.

20. Jelleyman C, Yates T, O'Donovan G, Gray LJ, King JA, Khunti K, et al. The effects of high-intensity interval training on glucose regulation and insulin resistance: a meta-analysis. Obesity reviews. 2015; 16(11): 942-61.

21. Shen Y, Xu X, Yue K, Xu G. Effect of different exercise protocols on metabolic profiles and fatty acid metabolism in skeletal muscle in high-fat diet-fed rats. Obesity. 2015; 23(5): 1000-6.

22. Rocha GL, Crisp AH, de Oliveira MR, Silva CA, Silva JO, Duarte AC, et al. Effect of High Intensity Interval and Continuous Swimming Training on Body Mass Adiposity Level and Serum Parameters in High-Fat Diet Fed Rats. The Scientific World Journal. 2016; 2016: 2194120. doi: 10.1155/2016/2194120.

23. Weston M, Taylor KL, Batterham AM, Hopkins WG. Effects of low-volume high-intensity interval training (HIT) on fitness in adults: a meta-analysis of controlled and non-controlled trials. Sports Medicine. 2014; 44(7): 1005-17.

24. Weston KS, Wisløff U, Coombes JS. High-intensity interval training in patients with lifestyle-induced cardiometabolic disease: a systematic review and metaanalysis. Br J Sports Med. 2014; 48(16): 1227-34.

25. Adams OP. The impact of brief high-intensity exercise on blood glucose levels. Diabetes, metabolic syndrome and obesity: targets and therapy. 2013; 6: 11322. doi: 10.2147/DMSO.S29222.

26. Bedford TG, Tipton CM, Wilson NC, Oppliger RA, Gisolfi CV. Maximum oxygen consumption of rats and its changes with various experimental procedures. Journal of Applied Physiology. 1979; 47(6): 1278-83.

27. Metcalfe RS, Babraj JA, Fawkner SG, Vollaard NB. Towards the minimal amount of exercise for improving metabolic health: beneficial effects of reduced-exertion high-intensity interval training. European journal of applied physiology. 2012; 112(7): 2767-75.

28. Karstoft K, Winding K, Knudsen SH, James NG, Scheel MM, Olesen J, Holst JJ, Pedersen BK, Solomon TP. Mechanisms behind the superior effects of interval vs continuous training on glycaemic control in individuals with type 2 diabetes: a randomised controlled trial. Diabetologia. 2014; 57(10): 2081-93. 
29. Cartee GD, Young DA, Sleeper MD, Zierath JU, Wallberg-Henriksson H, Holloszy JO. Prolonged increase in insulin-stimulated glucose transport in muscle after exercise. American Journal of PhysiologyEndocrinology And Metabolism. 1989; 256(4): E494-9.

30. Batacan RB, Duncan MJ, Dalbo VJ, Buitrago GL, Fenning AS. Effect of different intensities of physical activity on cardiometabolic markers and vascular and cardiac function in adult rats fed with a high-fat highcarbohydrate diet. Journal of Sport and Health Science. 2018; 7(1): 109-119.

31. Turek FW, Joshu C, Kohsaka A, Lin E, Ivanova G, McDearmon E, et al. Obesity and metabolic syndrome in circadian Clock mutant mice. Science. 2005; 308(5724): 1043-5.

32. Carter S, Caron A, Richard D, Picard F. Role of leptin resistance in the development of obesity in older patients. Clinical interventions in aging. 2013; 8: 829-44. doi: 10.2147/CIA.S36367.
33. Potteiger JA, Kirk EP, Jacobsen DJ, Donnelly JE. Changes in resting metabolic rate and substrate oxidation after 16 months of exercise training in overweight adults. International journal of sport nutrition and exercise metabolism. 2008; 18(1): 79-95.

34. Coles CA. Adipokines in healthy skeletal muscle and metabolic disease. Adv Exp Med Biol. 2016; 900: 13360. doi: 10.1007/978-3-319-27511-6_6.

35. Rodgers RJ, Ishii Y, Halford JC, Blundell JE. Orexins and appetite regulation. Neuropeptides. 2002; 36(5): 303-25.

36. Goodpaster BH, Kelley DE, Wing RR, Meier A, Thaete FL. Effects of weight loss on regional fat distribution and insulin sensitivity in obesity. Diabetes. 1999; 48(4): 839-47. 